\title{
Quadros Médicos: Egas Moniz, por José Malhoa
}

Medical Paintings: Egas Moniz, by José Malhoa

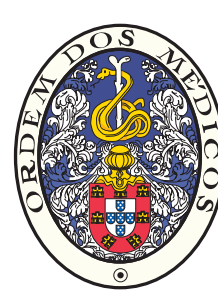

Victor OLIVEIRA 1

Acta Med Port 2014 Sep-Oct;27(5):669-671

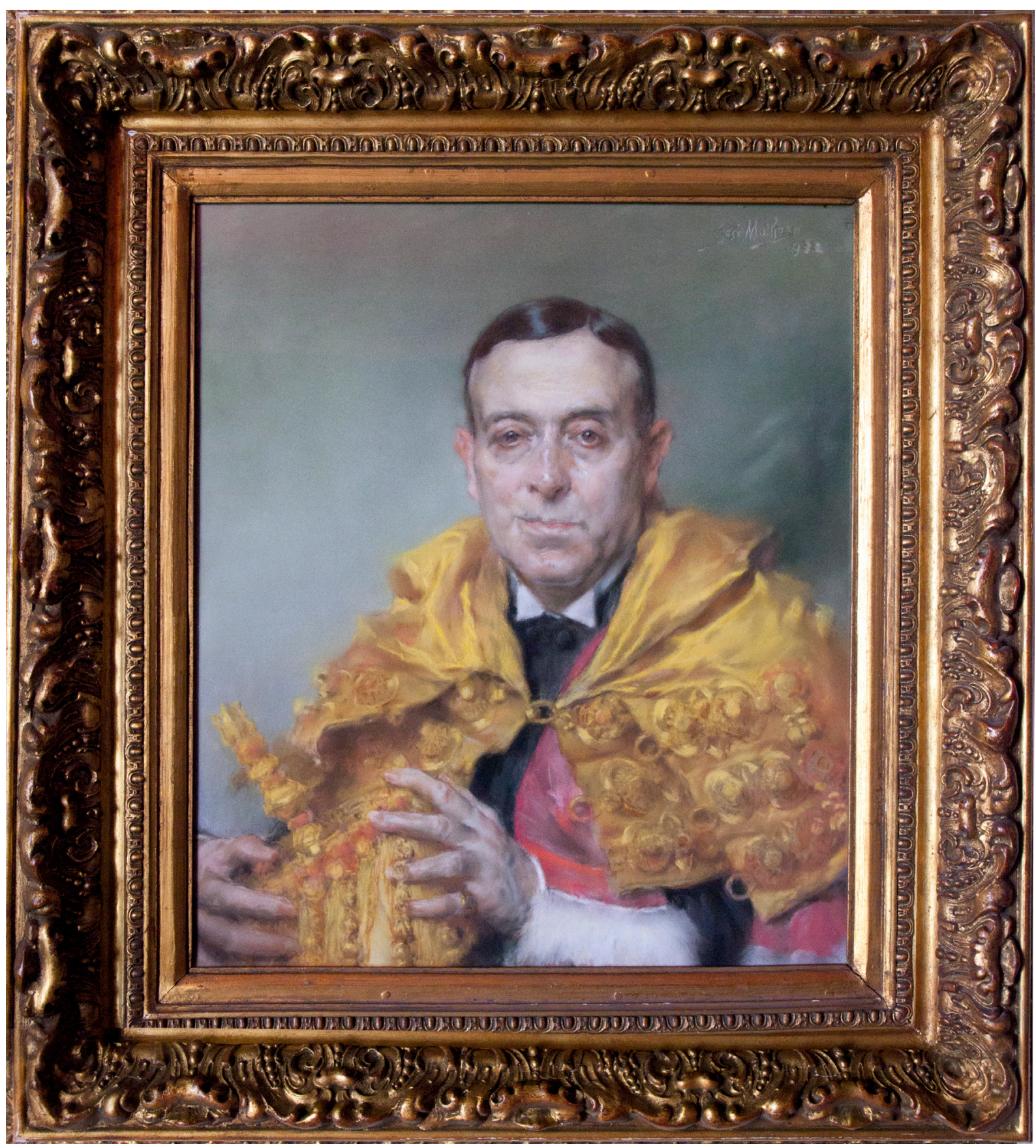

Figura 1 - "Retrato do Prof. Egas Moniz", José Malhoa, 1932, Pastel sobre papel, 60 x $51 \mathrm{~cm}$. Hospital de Santa Maria. Fotógrafo José Ângelo (FotoMatriz).

1. Regente da Cadeira de História da Medicina. Faculdade de Medicina. Universidade de Lisboa. Lisboa. Portugal. Recebido: 22 de Agosto de 2014 - Aceite: 25 de Agosto de 2014 | Copyright @ Ordem dos Médicos 2014 
Palavras-chave: History, 20th Century; Famous Persons; Paint; Neurology/history; Portugal; Psychosurgery/history. Keywords: História, Século XX; Neurologia/história; Pessoas Famosas; Pintura; Portugal; Psicocirurgia/história.

O retrato do Professor Egas Moniz foi desenhado por José Malhoa, começando a ser esboçado em 1930 e concluído em Março de 1932, conforme data inscrita junto à assinatura do pintor. Mestre Malhoa viria a falecer no ano seguinte, a 26 de Outubro de 1933, sendo um dos seus últimos trabalhos numa linha dedicada a figuras notáveis de diversas áreas da vida portuguesa da época.

Egas Moniz, retratado nos seus 58 anos, vivia um período áureo da sua carreira, pois acabara de publicar em Paris o primeiro livro dedicado à angiografia focado no diagnóstico dos tumores cerebrais ${ }^{1}$ e preparava já para o prelo o segundo, que seria publicado em 1934, sobre o estudo da circulação cerebral. ${ }^{2}$

José Malhoa retrata-o em meio corpo, presume-se que sentado, a $3 / 4$, envergando o traje de Professor da Universidade de Coimbra. Ressaltam aqui as cores luminosas tão características do Mestre: o amarelo dourado da samarra sobre o negro da beca, segurando nas mãos deformadas pela gota, a borla e o capelo que completam o traje académico. Aflora ainda uma estola grenat com franja branca de arminho. No quinto dedo da mão esquerda, o pintor esboça o anel de licenciatura com a pedra amarela, símbolo da Medicina.

O rosto rosado e cordial de Egas Moniz sobressai do fundo indiferente em nuances de verde. Fita o observador com olhar brilhante reforçado pelas pregas das pálpebras esboçando nos lábios um ténue sorriso com os cantos da boca retraídos. A coroar o contraste de cores, o seu bem penteado e lustroso capachinho negro.

No canto superior esquerdo distingue-se a assinatura do Mestre, datada de 1932 (Fig. 2).

Facto curioso é o traje de Catedrático da Universidade de Coimbra, envergado por Egas Moniz: este lograra a transferência para a capital em 1910, seria pois de esperar que se apresentasse com o traje académico de Lisboa. No entanto, o Professor manteve sempre uma forte dedicação à Universidade de Coimbra, várias vezes reiterada e é sempre neste traje que se apresenta, em fotos, ao longo da vida.

Segundo o próprio Malhoa, o trabalho terá agradado ao retratado pois, em carta de 1/4/1932 escreve: "... julgo que Ihe fez boa impressão: O Egas e família estão malucos com o retrato". ${ }^{3}$

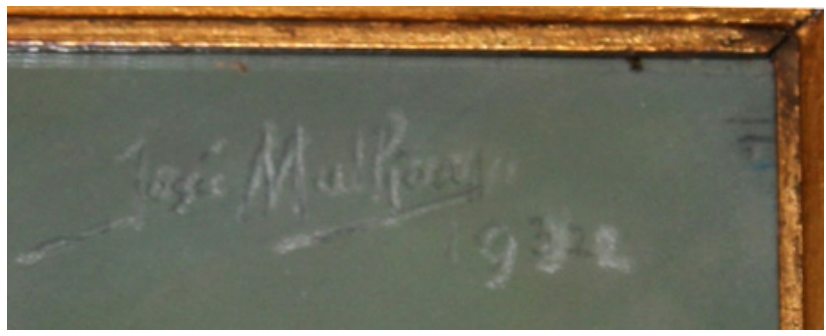

Figura 2 - Pormenor do retrato de Egas Moniz: assinatura de José Malhoa. (Foto do autor)
A amizade entre o Professor e o Mestre pintor vinha de longa data. Em 1927 Malhoa enviara a Egas Moniz um desenho cumprimentando-o pelo sucesso da apresentação da angiografia à comunidade científica internacional que tivera lugar na Societé Neurologique em Paris, cinco dias antes, a 7de Julho (Fig. 3). Nele se lia em desenho de um cartão preso a um foguete: "Ao Exmo. Sr. Dr. Egas Moniz mil felicitações pelo seu triunfo em Paris, José Malhoa, 12 de Julho de 1927". ${ }^{4}$

Por sua vez, em 19 de Junho de 1929, Egas Moniz discursara num banquete de homenagem a Malhoa e a cuja comissão organizadora presidira. A alocução foi posteriormente publicada em opúsculo sob o título "Ao Mestre José Malhoa". ${ }^{5}$ Nele, Egas Moniz ficciona uma viagem pelo País, de braço dado com o pintor, passando sucessivamente pelas cenas representadas nos seus principais quadros $e$ enaltecendo as virtudes do povo português rural.

Muito mais tarde, em 1955, ano da sua morte, Egas Moniz voltaria a recordar o Mestre em "A folia e a dor na obra de José Malhoa". ${ }^{6}$

Independentemente dos circunstancialismos do início da amizade, às razões de fundo não terá sido estranho

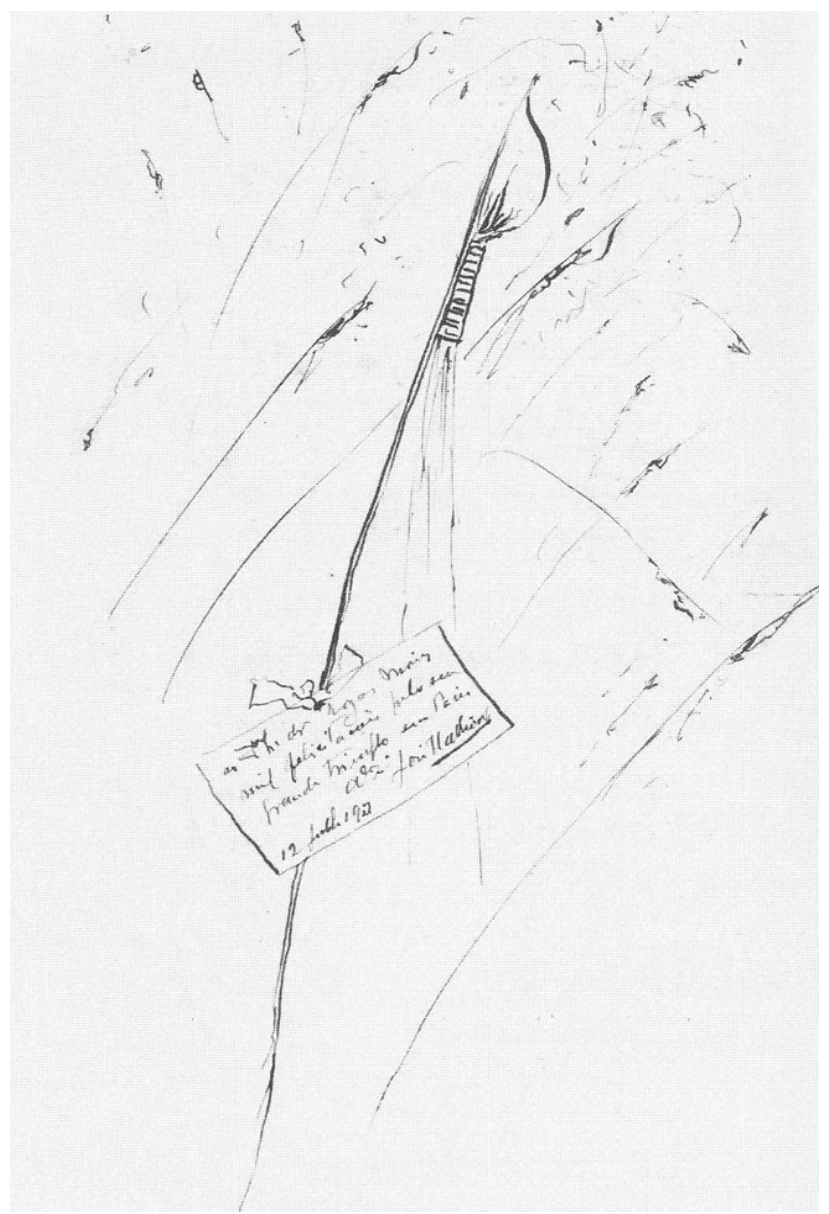

Figura 3 - Desenho enviado por José Malhoa ao Prof. Egas Moniz, felicitando-o pela apresentação da angiografia em Paris (1927). 
o estilo naturalista da obra de Malhoa com a representação realista de figuras e ambientes do povo simples das aldeias, envolvidos em cenas rurais do quotidiano, traduzidas em pinceladas fortes de cores vivas, fazem jus ao lugar de figura cimeira do naturalismo português.

A temática naturalista rural era cara a Egas Moniz já que este sentia um verdadeiro enleio pelos temas que lhe lembrassem as paisagens marinhoas da sua querida Avanca-natal.

No acervo da sua moradia em Avanca, hoje Casa-Museu, podem ver-se, nessa linha, obras de Silva Porto, Henrique Medina, Eduarda Lapa, Henrique Pousão, Falcão Trigoso e, claro, do próprio Malhoa.

\section{Do pintor José Malhoa ao escritor Júlio Diniz}

A sensibilidade de Egas Moniz pelo naturalismo era forte, não só na pintura, como também na escrita, consubstanciada no lirismo romântico de Júlio Diniz. Para mais, o escritor inspirara-se em personagens reais da então vila de Ovar, povoação vizinha de Avanca.

Certamente por isso, Egas Moniz viria a escrever em 1924, um espesso volume de cerca de 500 páginas intitulado "Júlio Diniz e a sua obra"7 da qual foram publicadas 6 edições.

Do entrosamento do naturalismo pictórico com o romantismo da escrita é exemplo o facto do pintor José Malhoa ter ido buscar ao escritor Júlio Diniz alguns personagens para os seus quadros, como o médico João Semana (1897) e Clara (1903), a lavadeira minhota de "As Pupilas do Sr. Reitor".

As preferências estéticas de Egas Moniz ficam claramente definidas nestas suas palavras publicadas no volume "Ao Lado da Medicina"8 a propósito da obra de Silva Porto: "As figuras que perpassam nas suas telas vêm dos campos, com a alma limpa de asperezas. Quando muito trazem o rosto tisnado pelas canículas, temperados pelas fainas salutares das lavouras e na conivência querida dos animais amigos. Nunca, nenhum dos discípulos do Mes- tre, se sentiu arrastado para a pintura dos reptos shakespearianos da desgraça, ou das catadupas frementes das convulsões sociais. As grandes paixões que dilaceram e gangrenam o espírito, mesmo aquelas que silenciosamente mirram a alacridade da vida sem exteriorizações violentas, não se adivinham nas obras dos artistas continuadores da orientação de Silva Porto".

A obra a pastel $(60 \times 51 \mathrm{~cm})$ ocupou um lugar destacado na sala de estar da moradia do Professor, na Avenida 5 de Outubro, sua última residência em Lisboa e foi cedido, mais tarde, pela viúva, ao pequeno museu do Centro de Estudos Egas Moniz - Serviço de Neurologia do Hospital de Santa Maria - piso 6, onde hoje se encontra, integrando um repositório evocativo da vida e obra do laureado com o Prémio Nobel da Medicina de 1949, organizado em 1957 pelo Prof. Almeida Lima com apoio da Fundação Calouste Gulbenkian. ${ }^{9}$

\section{AGRADECIMENTOS}

A Macieira Coelho, sobrinho-neto do Prof. Egas Moniz, pelas informações sobre o percurso do retrato.

A Lurdes Osório Gama Franco, funcionária administrativa que acompanhou o Serviço de Neurologia, sob a direcção do Prof. Almeida Lima, na transição do Hospital de Santa Marta para o Hospital de Santa Maria, pelas suas memórias sobre a criação do Museu.

A Acta Médica Portuguesa e a Ordem dos Médicos agradecem à Faculdade de Medicina da Universidade de Lisboa a gentil cedência dos direitos de reprodução deste quadro e a oportunidade de o divulgar.

\section{CONFLITOS DE INTERESSE}

O autor declara a inexistência de conflitos de interesse na realização do presente trabalho.

\section{FONTES DE FINANCIAMENTO}

Não existiram fontes externas.

\section{REFERÊNCIAS}

1. Moniz E. Diagnostic des tumeurs cérébrales et épreuve de l'encephalographie artérielle. Paris: Masson \& Cie;1931.

2. Moniz E. L'Angiographie Cérébrale. Ses applications et résultats en Anatomie, Physiologie et Clinique. Paris: Masson \& Cie; 1934.

3. Catálogo: Malhoa e Bordalo - Confluência de uma geração. Caldas da Rainha: Edição do Museu Malhoa; 2005.

4. Moniz E. Confidencias de um investigador científico. Lisboa: Edições Ática; 1949.
5. Moniz E. Ao Mestre Malhoa. Lisboa: Imprensa Libânio Silva; 1929.

6. Moniz E. A folia e a dor na obra de José Malhoa. Lisboa: Sep. Seara Nova;1955. p. 1305-6.

7. Moniz E. Júlio Diniz e a sua obra. Lisboa: Casa Ventura Abrantes; 1924.

8. Moniz E. Ao lado da Medicina. Lisboa: Bertrand; 1940.

9. Azeredo Perdigão J. Centenário de Egas Moniz. $2^{\circ}$ Volume. Lisboa: Ed. Comissão executiva das comemorações do centenário do nascimento do Prof. Egas Moniz; 1978. 


\section{Quadros Médicos: Egas Moniz, por José Malhoa}

Acta Med Port 2014:27:669-671

Publicado pela Acta Médica Portuguesa, a Revista Científica da Ordem dos Médicos

Av. Almirante Gago Coutinho, 151

1749-084 Lisboa, Portugal.

Tel: +351218428 215

E-mail: submissao@actamedicaportuguesa.com

www.actamedicaportuguesa.com

ISSN:0870-399X | e-ISSN: 1646-0758

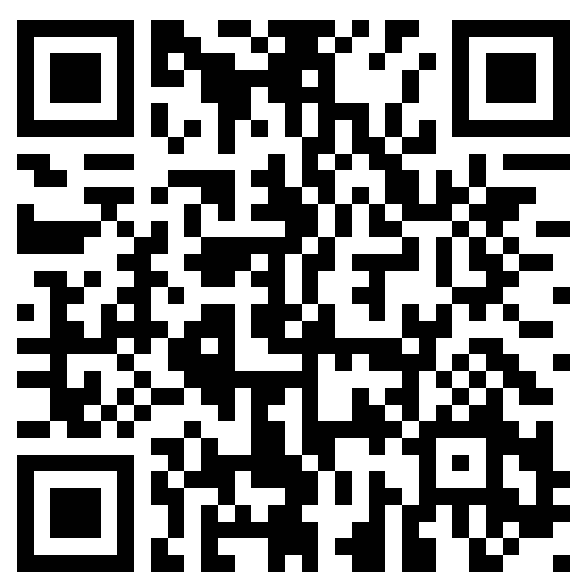

